\title{
Developmental pathways regulating wheat inflorescence architecture
}

\author{
Dobrovolskaya O.B. ${ }^{1,2 *}$, Dresvyannikova A.E. ${ }^{1,2}$, Volodina E.A. ${ }^{2}, K_{\text {rasnikov A.A. }}{ }^{3}$, \\ Orlov Yu. ${ }^{1}$, Watanabe N. ${ }^{4}$, Martinek P. ${ }^{5}$ \\ ${ }^{1}$ Institute of Cytology and Genetics, SB RAS, Novosibirsk, Russia \\ ${ }^{2}$ All-Russian Plant Quarantine Center, Bykovo, Ramenskoe distinct, Moscow region, Russia \\ ${ }^{3}$ Central Siberian Botanical Garden, SB RAS, Novosibirsk, Russia \\ ${ }^{4}$ College of Agriculture, Ibaraki University, Japan \\ ${ }^{5}$ Agrotest Fyto, Ltd., Kromeriz, Czech Republic \\ *e-mail: oxanad@bionet.nsc.ru
}

Wheat inflorescence architecture contributes to grain yield potential. The wheat inflorescence consists in a spike with a main axis carrying lateral sessile spikelets that are directly attached to the rachis and also a terminal spikelet. The spikelet constitutes the basal unit of the spike inflorescence. Wheat inflorescence architecture is determined by the activity of different meristem types and the timing of transitions between them. Although some of the genes controlling wheat meristem activities have been identified, understanding of the network of transcriptional regulators controlling this process is lacking. To address this, we used a set of classical and modern approaches of genetics and developmental biology, including high-throughput genotyping, light and electron microscopy and bioinformatics. We found the development of additional organs of the spikelet, glumes and flowers, in the T. jakubzinerii accession (shrl), which indicates disorders in spikelet meristem determinacy. The development of additional organs of the spikelet was not accompanied by a change in phyllotaxis. Thus, the function of the Shrl gene in the developing inflorescence of wheat is associated with determinacy of spikelet meristems. Genes Shrl and Shr2, RS, which determine the false-true branching of the ear and the false branching of the ear, are inherited independently. Thus, at least two different genetic pathways in wheat control the spikelet meristem determinacy.

Acknowledgements: This work was supported by grants from the Russian Foundation for Basic Research (project No. 18-04-00483). 